\title{
Design and Implementation of a Reverse Matrix Converter for Permanent Magnet Synchronous Motor Drives
}

\author{
Eunsil Lee* and Kyo-Beum Lee ${ }^{\dagger}$
}

\begin{abstract}
This paper presents the development of a system with a reverse matrix converter (RMC) for permanent magnet synchronous motor (PMSM) drive and its effective control method. The voltage transfer ratio of the general matrix converter is restricted to a maximum value of 0.866 , which is not suitable for applications whose source voltages are lower than the load voltages. The proposed RMC topology can step up the voltage without any additional components in the conventional circuit. Its control method is different from traditional matrix converter's one, thus this paper proposes control schemes of RMC by means of controlling both the generator and motor side currents with properly designed control loop. The converter can have sinusoidal input/output current waveforms in steady state condition as well as a boosted voltage. In this paper, a hardware system with an RMC for a PMSM drive system is described. The performance of the system was investigated through experiments
\end{abstract}

Keywords: Reverse matrix converter, Permanent magnet synchronous motor, Step-up voltage, Voltage transfer ratio, AC-AC converter

\section{Introduction}

The AC-AC conversion of electric power is widely used in industrial applications, such as adjustable-speed drives (ASDs), uninterrupted power supplies (UPSs), and utility interfaces. Back-to-back converters (BBCs), which are the most commonly used systems, have a dc link with energy storage elements, including a capacitor for the voltage dc link or an inductor for the current dc link. Because of the dc link storage element, this system has the advantage that both converter stages are decoupled for control purposes. On the other hand, the dc energy storage components in BBCs are bulky. Electrolytic capacitors in the voltage dc link typically occupy approximately 30 to $50 \%$ of the total volume of the converter for power levels above a few kilowatts, and they have limited lifetimes. In addition, the capacitor limits the power converter to high-temperature applications because the capacitors are temperature sensitive. Thus, general high-power capacitors cannot be used in some special applications, such as aircraft, deep-sea, or space systems. In addition, the inductors in the current dc link are generally bulkier and heavier than the link capacitor in the voltage dc link.

To achieve higher power density and reliability, it is reasonable to consider matrix converters (MCs) that perform AC-AC conversion without any intermediate energy storage elements. Conventional direct matrix converters

$\dagger \quad$ Corresponding Author: Dept. of Electrical and Computer Electronic Engineering, Ajou University, Korea. (kyl@ajou.ac.kr)

* Dept. of Electrical and Electronic Engineering, Ajou University, Korea. (ssilylife@hotmail.com)

Received: April 14, 2015; Accepted: July 8, 2015
(DMCs), which have an array of $\mathrm{m} \times \mathrm{n}$ bi-directional power switches to connect an $\mathrm{m}$-phase source to an $\mathrm{n}$-phase load, achieve voltage and current conversion in a single stage. The MCs have many desirable features, such as high power factor, sinusoidal input current, bi-directional power flow, and a compact design because of the lack of dc link energy storage components [1-4].

Another type of MCs investigated is the indirect matrix converter (IMC) or two-stage matrix converter [5]. IMC functions are equivalent to those of DMCs. IMCs consist of a front-end three-phase to two-phase current source rectifier (CSR) and a rear-end voltage source inverter (VSI). The number of switches of the CSR bridge of an IMC can be reduced $[6,7]$. In addition, an IMC can simplify the complex commutation problem by using a zero-current commutation method, which has the additional benefit of a reduction in switching losses. In addition, this topology enables multiple inputs and/or outputs to be used in an integrated power converter $[8,9]$.

In spite of these attractive advantages, MCs have not yet gained much attention in industries because of several unsolved problems. The critical drawback of the MC is that the voltage transfer ratio between the input and output is a maximum of $86 \%$ under the linear modulation region. Thus, the $\mathrm{MC}$ is not suitable for standard motors and distributed generation. Some alternative topologies and modulation strategies have been designed to improve the voltage transfer ratio. Several hybrid solutions have been proposed in order to obtain the unity voltage transfer ratio. These topologies combine the matrix converter and dc-dc buckboost choppers or some small dc energy storage elements [10]. However, these are complex power circuits with 
complex control strategies. Another solution is the Zsource matrix converter (ZMC), which employs a unique impedance network to couple the main circuit of the converter with the power source to achieve a buck-boost feature $[11,12]$. Unfortunately, ZMC topologies have some significant drawbacks, such as discontinuous current in the front of the Z-source network, and additional passive or active components.

In order to boost the voltage without adding any extra components, the concept of the reverse matrix converter (RMC) is presented in $[13,14]$, in which the MC can reverse the direction of power flow. In these papers, there are scoped for investigation in both grid-connected and islanded modes. In the RMC, the traditional voltage source stage is connected to the input three-phase source and the traditional current source stage is connected to the load. Thus, the voltage source rectifier (VSR) is controlled as an active front-end rectifier, where the zero voltage vector is applied to the VSR to boost the input voltage. The current source inverter (CSI) is modulated in the same way as the virtual dc link voltage, corresponding to the maximum output line-to-line voltages.

This paper focuses on the development of hardware and control strategy with a RMC for a PMSM drive system. The generator is modeled with a PMSM that is controlled by a separate vector control drive. The RMC can produce the desired ac output voltage, which is greater than the input voltage because of its voltage boosting capability. The speed of the PMSM is controlled using vector control with the proposed control strategy. The system's configuration, equivalent circuit, analysis, and control method are presented in detail. In this paper, design and implementation results demonstrate the superior performance of the proposed RMC-PMSM-based ASD system.

\section{Indirect Matrix Converter}

\subsection{Indirect matrix converter}

The structure of an IMC is shown in Fig. 1(a), with different examples of bi-directional switches shown in Fig. 1(b). Each bi-directional switch can conduct current in both directions and block voltage in both directions. The bi-directional switches were built using discrete semiconductor devices. There are four types of bidirectional switch arrangements that can be used in IMCs. The IMC consists of an array of power switches that is similar to that of the BBC. Unlike DMC, in an IMC it is possible to distinguish a rectifier stage and an inverting stage. The rectifier stage for the ac source, also known as CSR, consists of six bi-directional switches, where bidirectional power flow is possible. The inverter stage for the load consists of six IGBT and diode units, which is similar to a standard VSI. In addition, the IMC includes an LC filter in the input stage. This filter is needed to prevent over-voltage conditions and also to filter the highfrequency components of the input currents produced by the switching and the inductive nature of the load. The capacitors in this filter are very small in comparison with the dc link capacitor in a BBC.

The IMC synthesizes a positive dc link voltage by selecting a switching state in the rectifier that connects one phase to the point $P$ using one of the upper group switches and the other phase to the point $N$ using one of the lower group switches. The inverter stage uses the variable dc link voltage to generate the desired output voltage waveforms. In order to generate sinusoidal input and output waveforms, the IMC can be modulated using a space vector modulation (SVM) technique.

\subsection{Reverse indirect matrix converter}

Generally, the MC has been used for buck mode operation. With this structure, the voltage transfer ratio cannot exceed 0.866 under the linear modulation region. This paper presents the IMC under reverse power flow operation. This topology is called the RMC and its voltage transfer ratio always exceeds $1 / 0.866$. The RMC can achieve boost operation without any additional components. This topology consists of a VSR and a CSI as shown in Fig. 1(c). Inductors are on the input side and capacitors are at

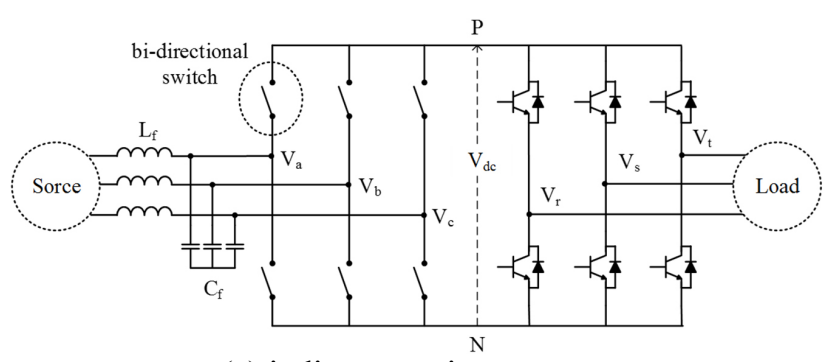

(a) indirect matrix converter

\begin{tabular}{|c|c|c|c|}
\hline $\begin{array}{c}\text { Common } \\
\text { collector }\end{array}$ & $\begin{array}{c}\text { Common } \\
\text { emitter }\end{array}$ & $\begin{array}{c}\text { Diode embedded } \\
\text { switch }\end{array}$ & $\begin{array}{c}\text { Two anti-parallel } \\
\text { RIGBTs }\end{array}$ \\
\hline
\end{tabular}

(b) example of bidirectional switch

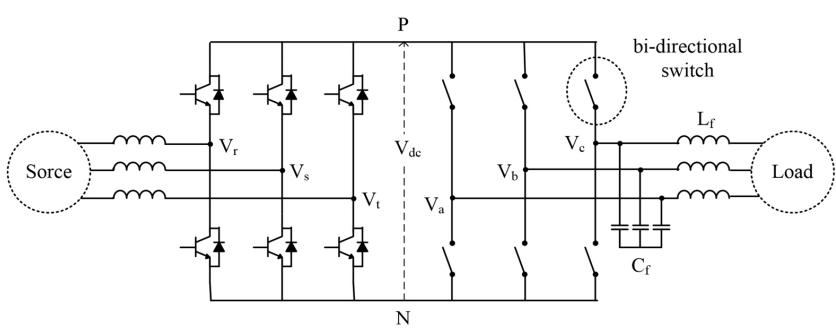

(c) reverse matrix converter

Fig. 1. Indirect matrix converter structure 


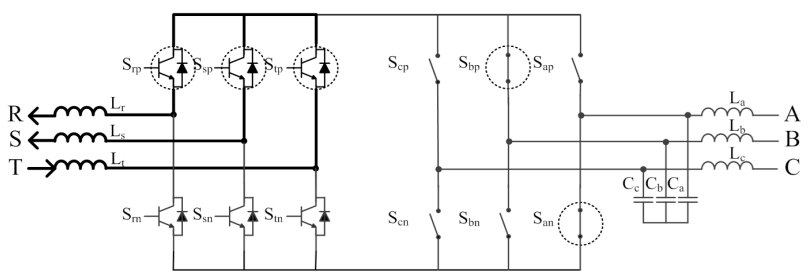

(a) $\mathrm{S}_{\mathrm{rp}}, \mathrm{S}_{\mathrm{sp}}, \mathrm{S}_{\mathrm{tp}}=\mathrm{ON}, \mathrm{S}_{\mathrm{bp}}, \mathrm{S}_{\mathrm{an}}=\mathrm{ON}$

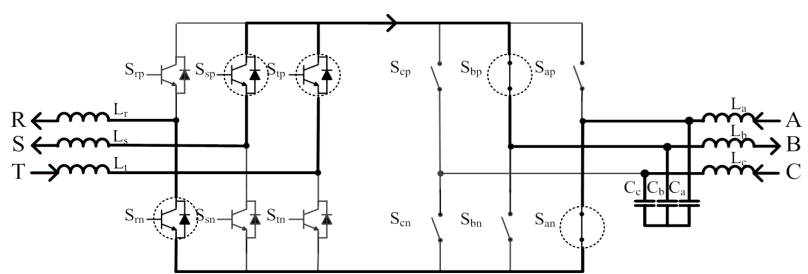

(b) $\mathrm{S}_{\mathrm{rp}}=\mathrm{OFF}, \mathrm{S}_{\mathrm{rn}}=\mathrm{ON}$

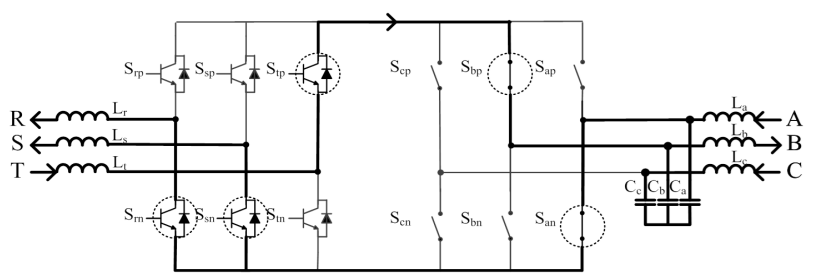

(c) $\mathrm{S}_{\mathrm{sp}}=$ OFF, $\mathrm{S}_{\mathrm{sn}}=\mathrm{ON}$

the output side. Because the switches are fed by current sources, the source inductance must never be interrupted. On the contrary, as the load has a capacitive nature, the output terminals should not be short-circuited. These rules are the opposite of the rules relating to the conventional IMC. Also almost all kinds of control strategies used in conventional IMC may be used [15].

The three phases of the source are designated as $V_{r}, V_{s}$ and $V_{t}$, and these are connected to the switches. The three load-side terminals are $V_{a}, V_{b}$ and $V_{c}$, and the filter is connected between the switches and the load.

In the following, a basic boosting operation is explained as shown in Fig. 2. For example, the control unit turns on the bi-directional switches $S_{r p}, S_{s p}$ and $S_{t p}$. Accordingly, the $R$-phase, $S$-phase and $T$-phase of the source are shortcircuited via the inductors $L_{r}, L_{s}$ and $L_{t}$, respectively, so that the short-circuit current flows and the inductors store energy in the form of a magnetic field. In this time, the switches $S_{b p}$ and $S_{a n}$ are in an ON state. Next, the control unit turns off the bi-directional switch $S_{r p}$ and turns on the bi-directional switch $S_{r n}$. Accordingly, the current is forced to flow through the $\mathrm{ON}$ switches and the filter. As a result, the total voltage available across the capacitor filter becomes larger than the source voltage by the emf induced in the inductors. The filter voltage exceeds the source voltage and hence the circuit acts as a step-up chopper and the energy stored in the source inductors is released to the filter capacitors as electrical energy. In this way, the control unit controls the switches to establish a current path from the source inductor to the filter capacitor.

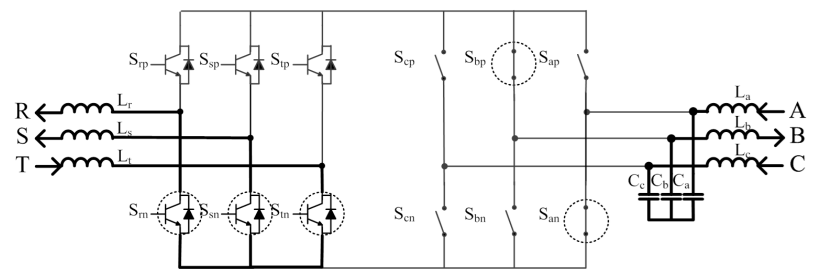

(d) $\mathrm{S}_{\mathrm{tp}}=$ OFF, $\mathrm{S}_{\mathrm{tn}}=\mathrm{ON}$

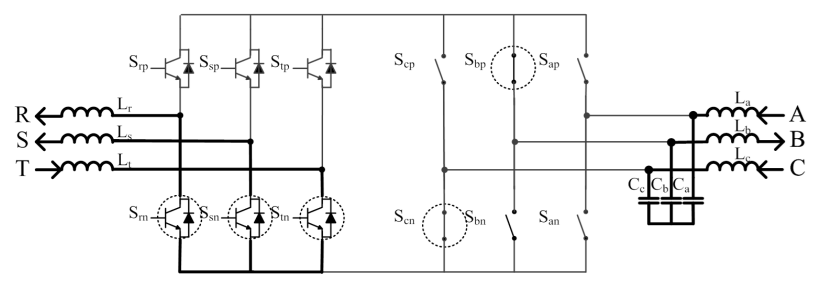

(e) $\mathrm{S}_{\mathrm{an}}=\mathrm{OFF}, \mathrm{S}_{\mathrm{cn}}=\mathrm{ON}$

Fig. 2. Sequence of switching $\left(V_{T}>0>V_{S}>V_{R}\right)$

The commutation of the inverter stage could happen during the time when the zero vectors in the rectifier stage are applied to synthesize the reference input voltage vectors, as shown in Fig. 2(d) and (e). Therefore, the rectifier stage could be switched into a free-wheeling state and then the inverter stage could commutate with zero dc link current. This has added benefit of a reduction in the switching losses in the inverter stage by applying the zero dc link current commutation.

\section{Proposed System}

The proposed hardware configuration of the RMC for a PMSM drive system is shown in Fig. 3. A power conversion module includes an RMC, which controls the speed of the motor and performs as a generator connection. A capacitor filter is employed to effectively suppress the output current ripples. The overall power system is controlled by a control unit, which is implemented with a DSP, an FPGA, and other peripheral circuits.

\subsection{Power converter}

The RMC consists of a VSR and CSI. These are connected to a common dc link without storage elements. The two-pack IGBT module (1), Hivron X2G50SD12P1), which consists of two IGBTs and two antiparallel diodes, is used to configure the rectifier stage and part of the inverter stage. The boost chopper (2), Hivron X2G50GL12P1) and the buck chopper (3), Hivron X2G50GR12P1) are used to configure the inverter stage, which includes the clamp diode. The pulse-width modulation (PWM) switching signals from the control unit drive each of the switches through the PWM interface, and a fault signal from the gate drivers is sent back to the control board to protect the system. 


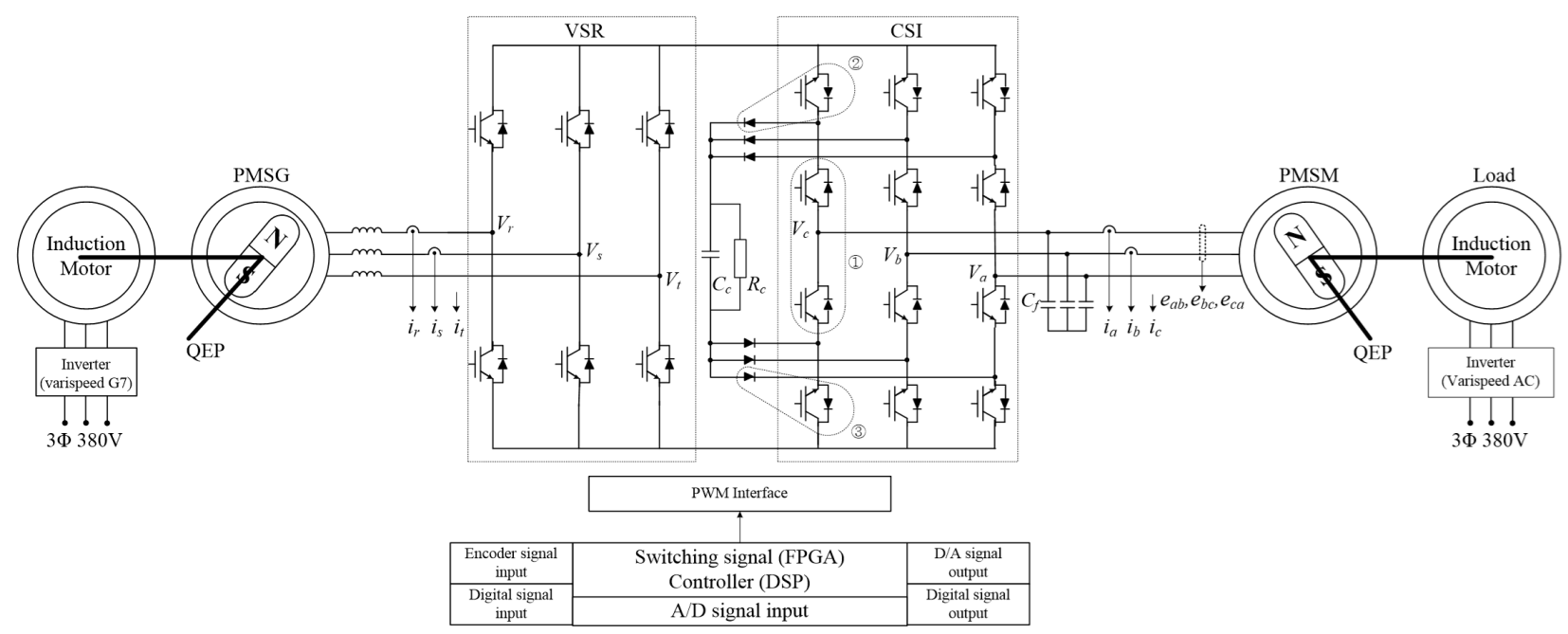

Fig. 3. Proposed hardware configuration of the reverse matrix converter for PMSM drive system.

To control the currents of the generator and the motor, two current sensors for each side $\left(i_{r}, i_{s}\right.$ and $\left.i_{a}, i_{b}\right)$ are installed. The third one $\left(i_{t}\right.$ and $\left.i_{c}\right)$ is simply the negative sum of the other two. In addition, two voltage sensors $\left(e_{a b}\right.$, $e_{b c}$ ) are installed to measure the line-to-line voltages of the motor. The third one $\left(e_{c a}\right)$ is simply the negative sum of the other two. These measured values are used to control the motor displacement angle.

\subsection{Control board}

The system is controlled by a control unit, which is implemented with a DSP (TI, TMS320C28346), an FPGA (Xilinx, XC6SLX45CSG324), and other peripheral circuits, as shown in Fig. 4. The DSP communicates with a computer through a JTAG. The quadrature encoder pulse (QEP) signals represent the rotational angle of the motor and generator.

To control the power module of the system, the controller should be able to drive 18 switches independently, which means that 18 separate PWM channels are required. Hence, an additional FPGA is employed, which communicates with the DSP through a 32-bit data bus. The FPGA receives

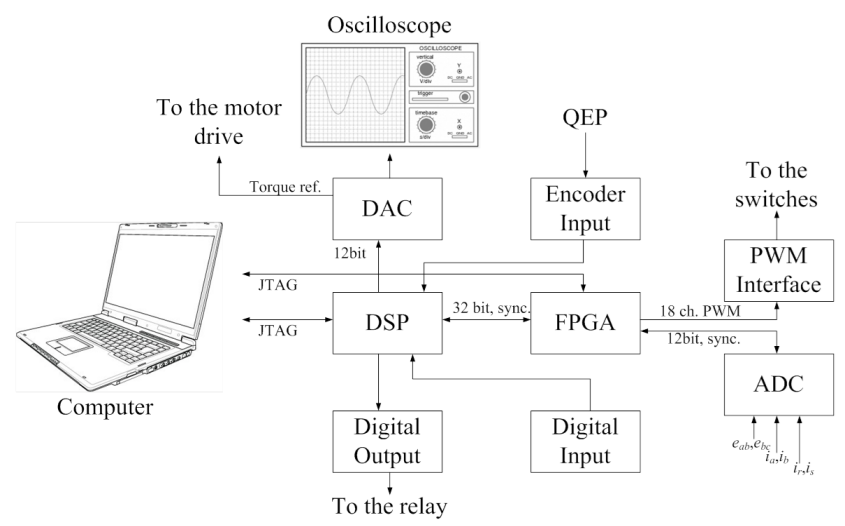

Fig. 4. Functional block diagram of the control unit. duty information from the DSP and produces corresponding PWM signals. The DSP provides a synchronizing signal from the FPGA. With this synchronizing signal, the ADC gets new measured values and the DSP starts a new control period. The PWM interface board is also implemented to provide isolation and to match the voltage level of the PWM signals, because the FPGA produces positive logic 3.3-V PWM signals but the power converter requires $15-\mathrm{V}$ PWM signals.

To convert the analog signal to a digital signal, the six $\mathrm{ADC}$ channels are required (four for the currents and two for the voltages). Unfortunately, the TMS320C28346 has no internal ADC circuit. Therefore, a separate ADC board is implemented. This board performs sample-and-hold functions at the same time that it receives a synchronizing signal from the FPGA. The analog signals are then converted into 12-bit digital signals and transferred to the DSP.

Other peripheral circuits are also implemented in the control board, such as a digital signal output that controls the magnetic connector on the source side, a digital signal input, and isolation circuits.

\subsection{Generator-load set}

The demand for permanent magnet motors is increasing in servo systems, industrial robots, electric vehicles and wind power systems. This is because there're many advantages such as high efficiency, wide driving range, high output torque per unit volume, etc. The input to the $\mathrm{RMC}$ is a variable frequency/voltage generator. It is assumed that the generator is a permanent magnet machine that operates at different speeds when driven by a prime motor such as gas turbine or wind turbine [16]. Generally, the speed and angle of this generator can be identified by both the characteristics of the generator and its operating parameters. In this system, an induction motor that represents a turbine is fed to the general inverter (Yaskawa 
Varispeed G7) with arbitrary velocity.

The load can be consisted of various consumer loads, such as lighting, heaters, and fans. The reference load torque for the motor is converted into the corresponding analog signal through the D/A converter board and sent to the load motor drive, which controls the torque of the induction motor. In this system, the load is fed to the general inverter (Yaskawa Varispeed AC).

\subsection{Filter and protection circuit}

The large dc link capacitors of the $\mathrm{BBC}$ are replaced by a small filter in the MC. The filter is needed in order to reduce the harmonic distortion of the line current to an acceptable level, and it performs as an interface between the MC and loads. This feature avoids radical changes in the converter output voltage during each PWM cycle, and prevents unnecessary harmonic currents from flowing into the loads. In this system, a capacitor filter is used as the output filter. It consists of three $7-\mu \mathrm{F}$ capacitors in a starconnection [17]. This value was not optimized, rather it was chosen from those available in the laboratory.

Like any other converter, the matrix converter needs to be protected against over-voltages and over-currents that might be destructive for its semiconductor devices. A common protection circuit consists of one capacitor connected to all input and all output lines through two diode bridges. This protects the switches from the surge coming from the input-side $\mathrm{AC}$ line as well as from the surge on the output. In this system, only six diodes are used to protect the switches [18]. The principle is that the $\mathrm{RMC}$ allows freewheeling of current from load or dc link while the antiparallel diodes from the rectifier stage allow natural freewheeling of source currents into the dc link like a standard VSI. Since the voltage of clamp capacitor is increased during each switching operation, it is required for the discharge of the capacitor energy. An efficient energy removal method is to use auxiliary circuit across the capacitor when the clamp voltage gets beyond a preselected level. Here we have used a resistor in parallel with the clamp capacitor to discharge of the clamp energy. The selected clamp capacitance is $22 \mu \mathrm{F}$.

\section{Proposed Control Strategies}

For the RMC operation of the PMSM drive system, there are mainly two different control strategies; one is an inverter control strategy and the other one is a rectifier control strategy. Both of the control strategies for load-side and source-side are explained in this section. Furthermore, switching modulation of the RMC is briefly explained. The overall control system proposed in this paper is shown in Fig. 5.

\subsection{Load-side control}

One of the best control strategies to achieve fast PMSM performance in terms of speed and/or torque is fieldoriented control (FOC), also called vector control. The basic principle of the FOC technique is decoupling the torque-current component from the flux-current component by the $q$-axis and $d$-axis, respectively [19]. Thus, these components can be controlled independently. The main goal of applying the FOC technique is increasing the motor torque for a given ampere rating. In PMSM, mainly it is achieved by setting the motor space angle to zero. Consequently, it can be done by setting the d-axis current component to zero, and the motor torque is adjusted by controlling only the $q$-axis current component. If the load is an IPMSM (Interior PMSM) or induction motor, it can realize the optimal torque control using the control of the appropriate $d$-axis current component.

The scheme of the RMC-PMSM control system is shown in Fig. 5 and Fig. 6; it consists of a speed-outputloop and a current-inner-loop. In the speed loop, the difference between the speed reference $\left(\omega_{m}{ }^{*}\right)$ and the motor speed $\left(\omega_{m}\right)$ is used to calculate a reference torque $\left(T_{e}{ }^{*}\right)$,

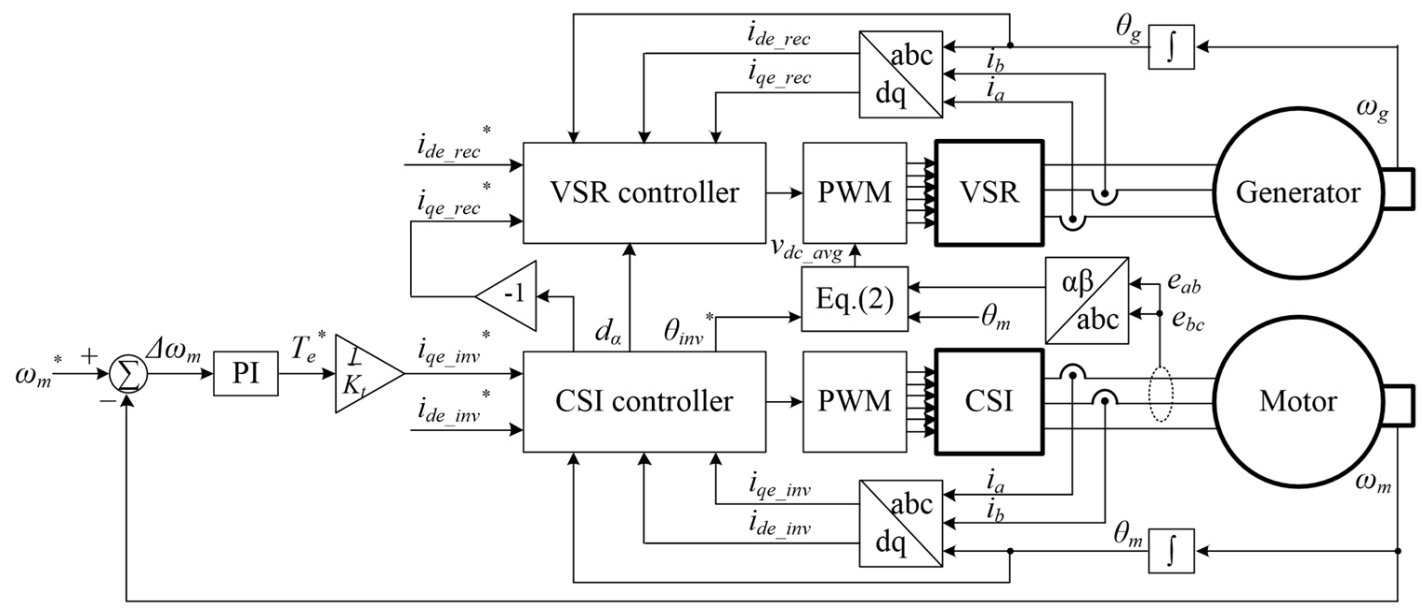

Fig. 5. Block diagram of the overall control scheme for the reverse matrix converter system. 


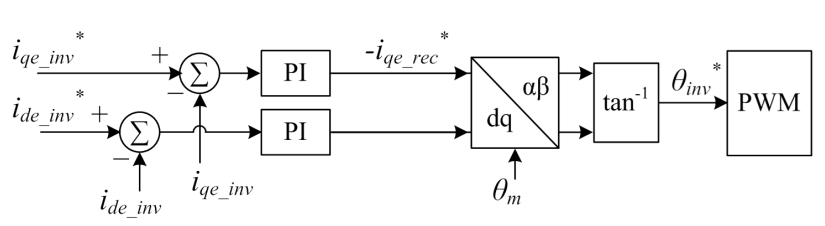

Fig. 6. Block diagram of the CSI control scheme for the load side.

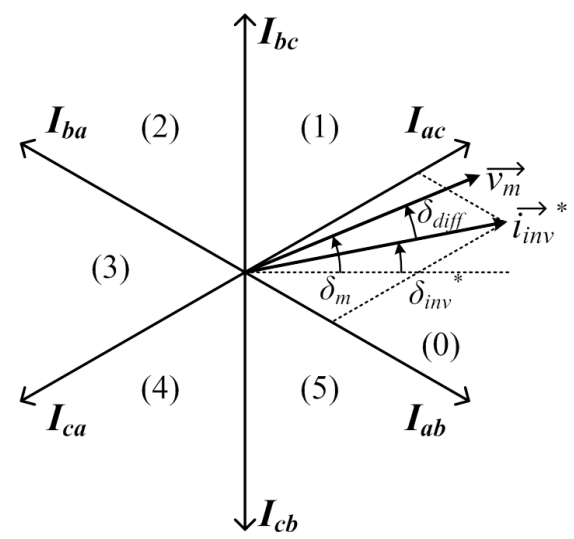

Fig. 7. Block diagram of the CSI control scheme for the load side.

which is proportional to the $q$-axis current. The d,q projections of the stator phase currents $\left(i_{\text {de_ } i n v}, i_{q e_{-} i n v}\right)$ are then compared to their reference values $\left(i_{\text {de }}\right.$ inv ${ }^{*}, i_{q e}$ inv $\left.{ }^{*}\right)$ and corrected through the PI current controllers. The outputs of the current controllers are passed through the inverse transformation and a reference current theta $\left(\theta_{i n v}{ }^{*}\right)$ is inserted in the modulation technique.

The CSI is controlled on the basis of the reference current vectors of the load. Fig. 7 shows the space vector diagram of the CSI. The subscript in each space vector denotes its relative switching state. Assume that the reference current vector $\left(\delta_{i n v}\right)$ is located in sector 0 and lags behind the output voltage vector $\left(\delta_{m}\right)$ with the difference angle $\left(\delta_{\text {diff }}\right)$. The angle of the reference current space vector within the actual hexagon sector $\left(S_{n u m}\right)$ is calculated as

$$
\delta_{i n v}=\theta_{i n v}-\frac{\pi}{3} S_{n u m}
$$

In the CSI, the zero vectors are not used. Thus the duty ratio of the one active vector for the CSI stage is determined as follows:

$$
\delta_{\alpha}=\cos \left(\delta_{i n v}{ }^{*}-\frac{2 \pi}{3}\right) / \cos \left(\delta_{i n v}{ }^{*}\right) .
$$

Depending on the location of the reference current vector, appropriate active switching vectors are chosen. For example in sector 0 , phase $a$ is connected to the positive dc link and phase $b$ is connected to the negative dc link during $\mathrm{d}_{\alpha}$ in one switching period. During the complementary time $\left(1-\delta_{\alpha}\right)$ in one switching period, phase $a$ and phase $c$ are connected to the positive and negative dc link, respectively.

The average dc link voltage in one sampling period can be obtained as

$$
v_{d c_{-} a v g}=\frac{3}{2} \frac{V_{m}}{\cos \left(\delta_{i n v}{ }^{*}\right)} \cos \left(\delta_{\text {diff }}\right) .
$$

\subsection{Source-side control}

A control strategy for the generator-side converter is developed. It can also realize the optimal control using the control of the appropriate $d$-axis current component. In this paper, in order to achieve the maximum torque per ampere, the reference $d$-axis current $\left(i_{d d_{\text {_inv }}}{ }^{*}\right)$ is set to zero. Thus, there will be a linear relationship between the electromagnetic torque and the $q$-axis current $\left(i_{q e}\right.$ inv $)$, such that the electromagnetic torque can be easily controlled by regulating the $q$-axis current. This reference $\left(i_{q e_{i} i n v}{ }^{*}\right)$ means the amount of power that the generator must supply to the loads. The reference stator voltages are then achieved by a PI controller in the current control loops as shown in Fig. 8.

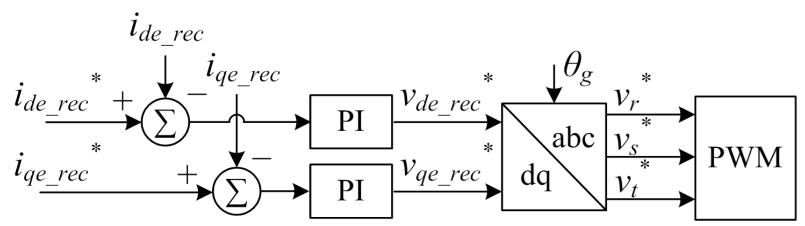

Fig. 8. Block diagram of the VSR control scheme for the source side.

\subsection{Carrier-Based PWM}

In carrier-based PWM [20, 21], the PWM signals are generated by comparing a triangular carrier waveform $\left(M_{t r i}\right)$ to a reference modulating signal $\left(M_{x y}\right)$, where $x \in(a$, $b, c), y \in(p, n)$. The modulating signals for the inverter stage are calculated on the basis of the duty cycles. Unlike the modulating signals for the rectifier stage, which are calculated on the basis of the reference voltages, the inverter stage modulating signals are calculated on the basis of the average dc link voltage and duty cycles. The modulating signals at sector 0 can be obtained using the duration of the gate pulses $\left(T_{x y}\right)$ in a sampling period $\left(T_{s}\right)$ for switches $\left(S_{x y}\right)$ as follows:

$$
\begin{gathered}
T_{a p}=T_{s} ; \quad T_{b p}=0 ; \quad T_{c p}=0 ; \\
T_{a n}=0 ; \quad T_{b n}=d_{\alpha} T_{s} ; \quad T_{c n}=\left(1-d_{\alpha}\right) T_{s} ; \\
M_{a p}=1 ; \quad M_{b p}=0 ; \quad M_{c p}=0 ; \\
M_{a n}=0 ; \quad M_{b n}=d_{\alpha} ; \quad M_{c n}=M_{b n} ; \\
S_{x y}= \begin{cases}1, & M_{x y} \geq M_{t r i}, \\
0, & M_{x y}<M_{t r i},\end{cases}
\end{gathered}
$$

where the PWM signal for switch $S_{c n}$ is complementary to 


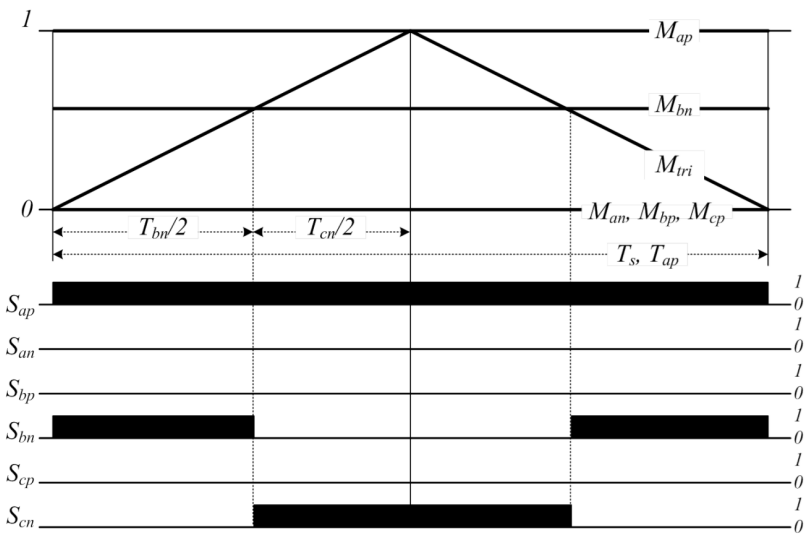

Fig. 9. Modulation signals and carrier signals for the inverter stage and switching sequence.

that of switch $S_{b n}$.

Fig. 9 shows modulating signals and a triangular carrier signal to generate PWMs for the inverter stage and its switching sequence. It can be seen that the switch $S_{a n}$ is always ON and switches $S_{a n}, S_{b p}$ and $S_{c p}$ remain OFF. On the other hand, switches $S_{b n}$ and $S_{c n}$ are ON only during $T_{b n}$ and $T_{c n}$, respectively. The same procedure can be applied to the other five sectors.

In the rectifier stage, the sinusoidal references are added with an offset voltage before being compared to the carriers to achieve the performance of a SVM. The offset voltage can be expressed as

$$
v_{s n}^{*}=-\frac{v_{\max }+v_{\min }}{2},
$$

where, $v_{\max }=\max \left(v_{r}^{*}, v_{s}^{*}, v_{t}^{*}\right), \mathrm{v}_{\min }=\min \left(v_{r}{ }^{*}, v_{s}^{*}, v_{t}^{*}\right)$.

In order to create the gate signal, two modulating signals $\left(M_{x(y)}\right)$ are needed for each switch in each phase, where $x$ $\in(r, s, t), y \in(1,2)$. The two modulating signals of the $x$ phase for switches $\left(S_{x p}\right)$ can be obtained as follows:

$$
\begin{aligned}
& M_{x(1)}=\frac{\left(-2\left(1-d_{\alpha}\right) \frac{v_{x}^{*}+v_{s n}{ }^{*}}{v_{d c_{\_} a v g}}+d_{\alpha}+1\right)}{2}, \\
& M_{x(2)}=\frac{\left(-2 d_{\alpha} \frac{v_{x}{ }^{*}+v_{s n}{ }^{*}}{v_{d c_{\_} a v g}}-\left(1-d_{\alpha}\right)+1\right)}{2}, \\
& S_{x(y)}= \begin{cases}1, & M_{x(y)} \geq M_{t r i}, \\
0, & M_{x(y)}<M_{t r i},\end{cases} \\
& S_{x p}=S_{x(1)} \overline{X O R} S_{x(2)} .
\end{aligned}
$$

The modulating signals must synchronize with the inverter stage switching, so as to produce sinusoidal waveforms for the matrix converter. To realize this, the rectifier stage state contains the information about the duty cycle in inverter stage. Thus, it includes the zero

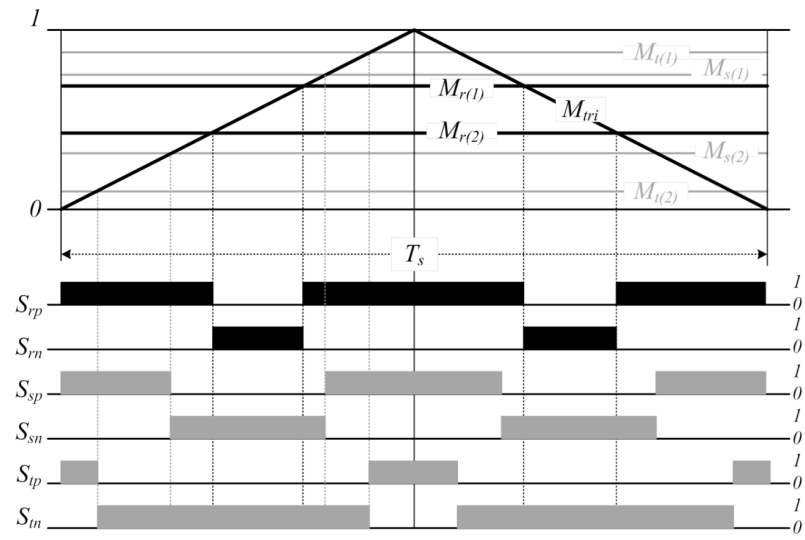

Fig. 10. Modulation signals and carrier signals for the rectifier stage and switching sequence.

commutation of the inverter stage. Comparing the upper signal $\left(M_{r(l)}\right)$ with the carrier then results in one of the gating signals for $S_{x(I)}$, whereas doing the same with the lower signal $\left(M_{r(2)}\right)$ results in another gating signal for $S_{x(2)}$. The gating signal for $S_{x p}$ is generated by performing logical operations using Eq. (9) and (10). The switch $S_{x n}$ is complementary to that of switch $S_{x p}$.

\section{Experiments}

The system introduced in Section III was built, and Fig. 11 shows actual pictures of the system. The system consists of two-MG set, a power converter, a C-filter, and a control board. Table 1 shows the circuit parameters used for this system.

Fig. 12 shows the experimental steady-state waveforms of the generator and motor when a generated voltage of

\begin{tabular}{|c|c|c|}
\hline \multicolumn{2}{|r|}{ Parameters } & values \\
\hline \multirow{5}{*}{ Generator } & Stator resistance & $0.099 \Omega$ \\
\hline & Stator d-axis inductance & $4.07 \mathrm{mH}$ \\
\hline & Stator q-axis inductance & $4.65 \mathrm{mH}$ \\
\hline & No. of poles & 6 \\
\hline & Back emf constant & $167 \mathrm{~V} / \mathrm{krpm}$ \\
\hline \multirow{6}{*}{ Motor } & Stator resistance & $0.349 \Omega$ \\
\hline & Stator d-axis inductance & $13.17 \mathrm{mH}$ \\
\hline & Stator q-axis inductance & $15.60 \mathrm{mH}$ \\
\hline & No. of poles & 6 \\
\hline & Back emf constant & $274 \mathrm{~V} / \mathrm{krpm}$ \\
\hline & Load inductance & $2 \mathrm{mH}$ \\
\hline Filter & Filter capacitance & $7 \mu \mathrm{F}$ \\
\hline \multirow{2}{*}{$\begin{array}{l}\text { Clamp } \\
\text { circuit }\end{array}$} & Clamp capacitance & $22 \mu \mathrm{F}$ \\
\hline & Clamp resistance & $20 \mathrm{k} \Omega$ \\
\hline \multirow{2}{*}{$\begin{array}{l}\text { Switching } \\
\text { Frequency }\end{array}$} & Rec. stage sw. frequency & $20 \mathrm{kHz}$ \\
\hline & Inv. stage sw. frequency & $10 \mathrm{kHz}$ \\
\hline \multicolumn{2}{|c|}{ Sampling Period } & $100 \mu \mathrm{s}$ \\
\hline
\end{tabular}
approximately $150 \mathrm{~V}$ is applied to the system. The reference speed of the motor is $1000 \mathrm{rpm}$ and the load torque is $5 \mathrm{Nm}$. Fig. 12(a) shows the line-to-line voltage on

Table 1. Hardware specifications 


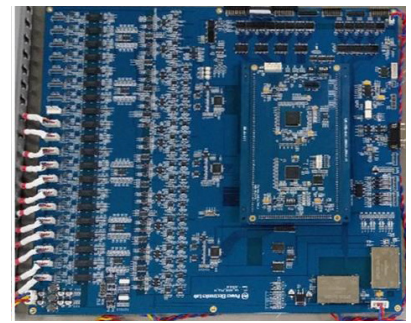

(a) control unit

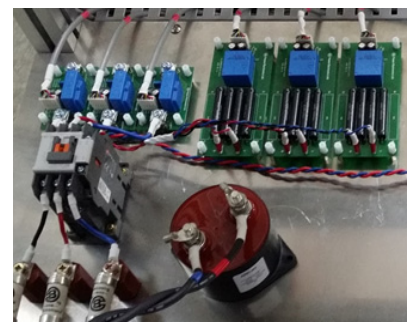

(b) sensors and etc.

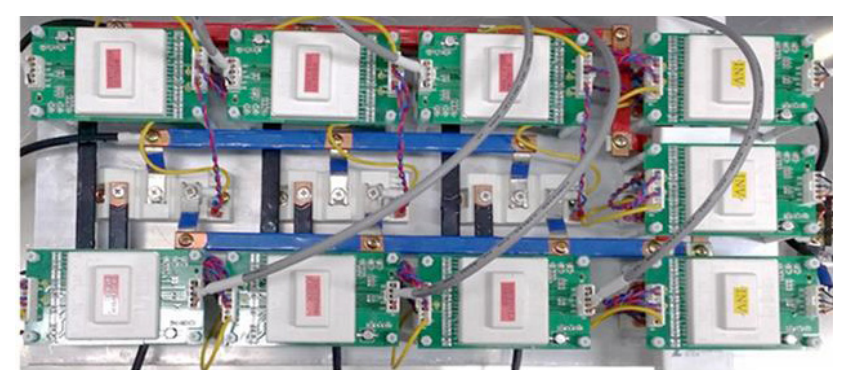

(c) switches and gate drivers

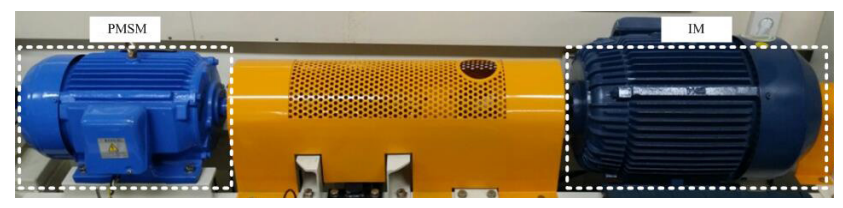

(d) motor-load set

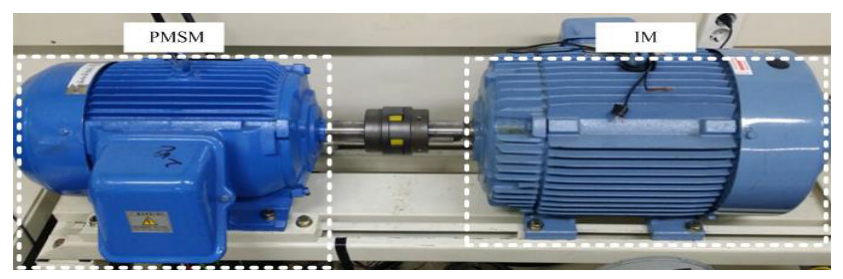

(e) generator set

Fig. 11. Actual hardware experimental set.

the generator side and VSR side. Fig. 12(b) and (c) show the phase voltage and phase current in the generator side and motor side, respectively. The phase current is mostly sinusoidal and practically in phase with the phase voltage.

Fig. 12(d) shows the phase current in the CSI side and motor side. The capacitor filter between the CSI and the motor smoothes the current and the fundamental component is clearly recognized.

Fig. 13 shows the speed step responses of the motor due to the change in reference speed from $600 \mathrm{rpm}$ to 1400 $\mathrm{rpm}$ and to $1000 \mathrm{rpm}$. The controller-based drive system can follow the command speed quickly with negligible overshoot and almost zero steady state error.

Fig. 14 shows the line-to-line voltage and phase current in the generator side and in the motor side as well when the generator voltage changes from $72 \mathrm{~V}$ to $106 \mathrm{~V}$. The generator-side current is noted to be decreased as the generator side voltage increases. The voltage and current values in the motor side are kept to be constant because

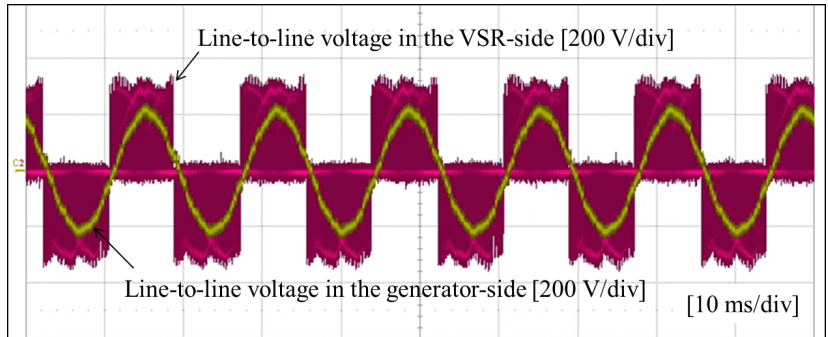

(a) line-to-line voltage in the generator and VSR side

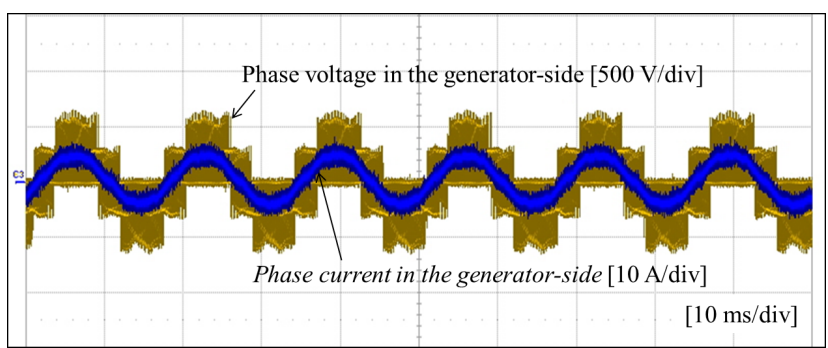

(b) phase voltage and phase current in the generator-side

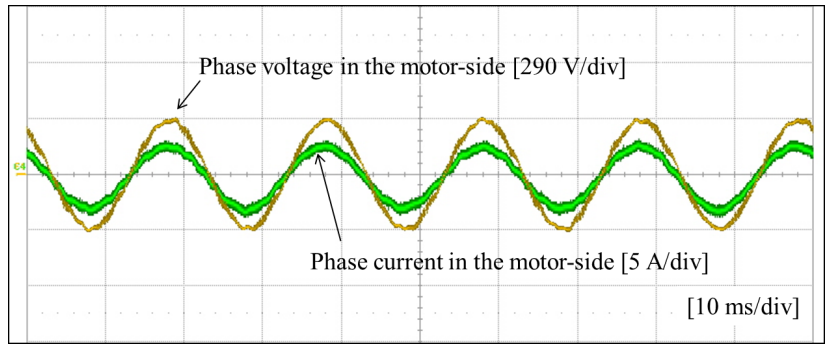

(c) phase voltage and phase current in the motor-side

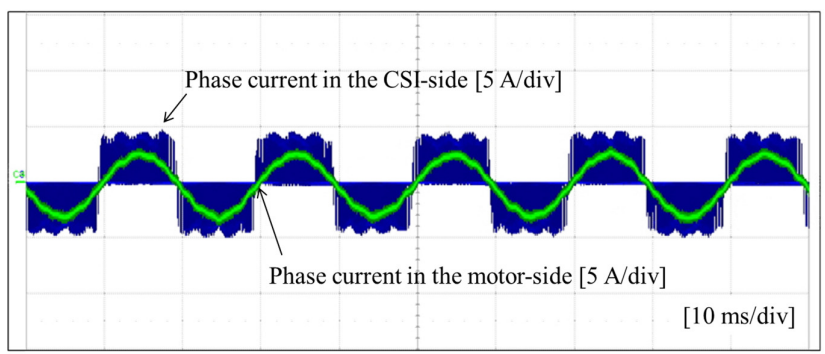

(d) phase current in the CSI and motor side

Fig. 12. Experimental waveforms of steady state condition.

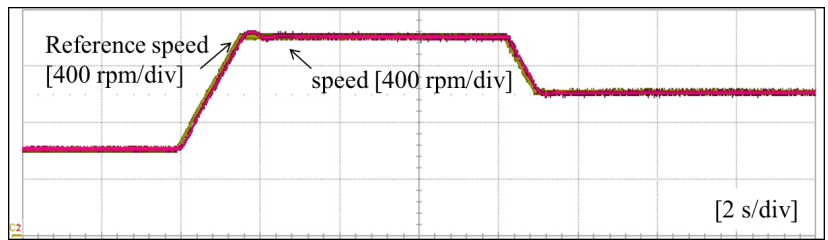

Fig. 13. Experimental waveforms of speed response from $600 \mathrm{rpm}$ to $1400 \mathrm{rpm}$ and to $1000 \mathrm{rpm}$.

motor speed and load are fixed at $1000 \mathrm{rpm}$ and $6 \mathrm{Nm}$, respectively. The frequency of the generator side is changed from $30 \mathrm{~Hz}$ to $45 \mathrm{~Hz}$. The voltage in the motor side was larger than the voltage in the generator side, with 


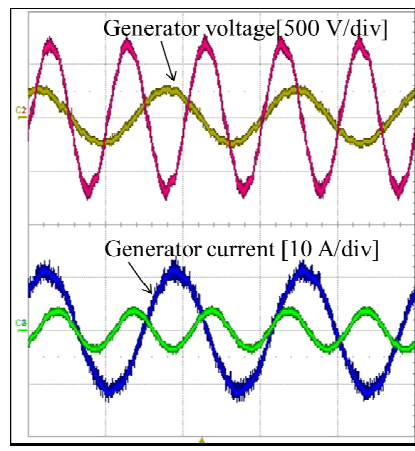

(a) $72 \mathrm{~V}$

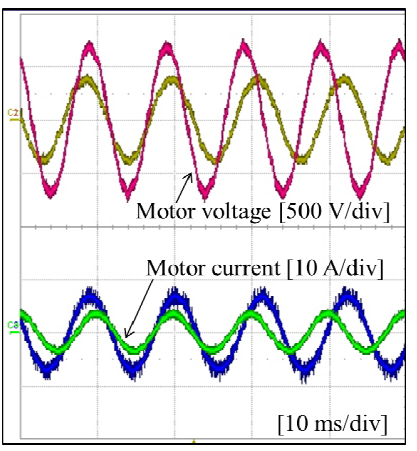

(b) $106 \mathrm{~V}$
Fig. 14. Experimental waveforms at different generated voltages.

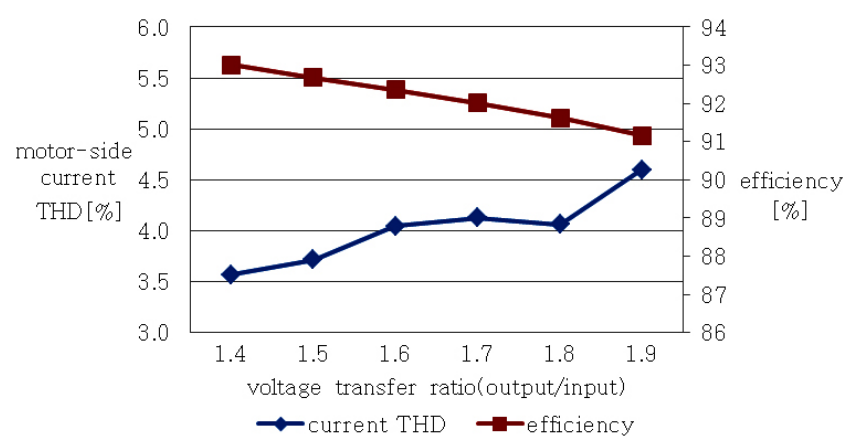

Fig. 15. Relationship between the THD of the current in the motor side and efficiency, and the voltage transfer ratio.

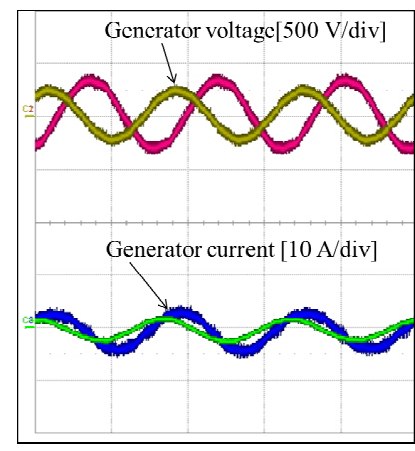

(a) $3 \mathrm{Nm}$

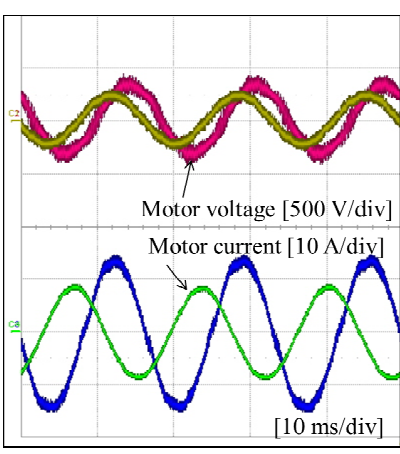

(b) $18 \mathrm{Nm}$
Fig. 16. Experimental waveforms at different load torques.

a voltage transfer ratio of 2.7 and 1.8 , respectively.

Fig. 15 shows the relationship between the THD of the motor-side current and efficiency and also the voltage transfer ratio at the same motor current. Because of the low semiconductor losses in the RMC, the efficiency of this converter is the highest at low voltage transfer ratios. Furthermore, from this analysis, it is seem that the proposed method can achieve high efficiency and low THD.

Fig. 16 shows the line-to-line voltage and phase current in the generator side and motor side when the load torque changes from $3 \mathrm{Nm}$ to $18 \mathrm{Nm}$. The currents are noted to

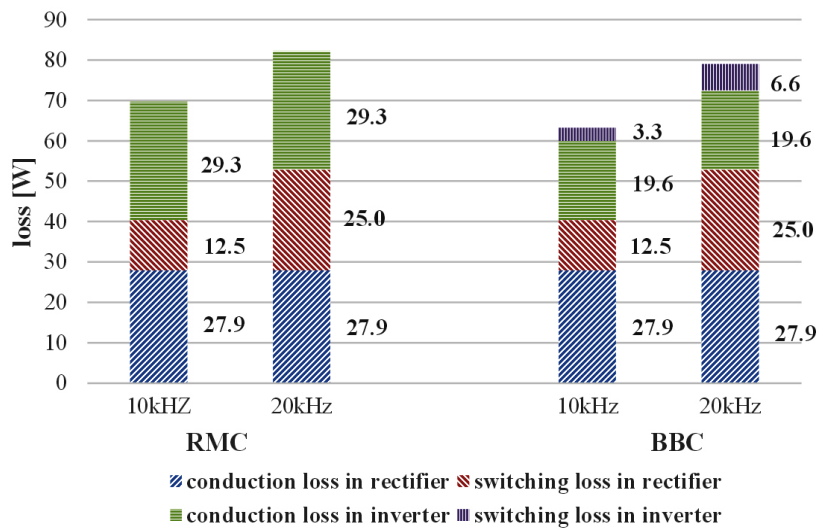

Fig. 17. Loss analysis of the proposed RMC and BBC

increase as the load torque increases. The voltage in the motor side was larger than the voltage in the generator side, and the voltage transfer ratio is 1.4 .

Fig. 17 shows the loss analysis of the proposed RMC and $\mathrm{BBC}$ when the input voltage is fixed at $235 \mathrm{~V}$, motor speed and load are fixed at $1550 \mathrm{rpm}$ and $12.2 \mathrm{Nm}$, respectively. It can be seen that the loss of the RMC is more than $\mathrm{BBC}$. This is a limitation of a matrix converter using a number of switches, it can be able to overcome this by efforts such as reducing the number of switches.

\section{Conclusion}

In this paper, the development of a system with an RMC for a PMSM drive was described. The hardware components of the system were described and the system's control schemes regarding RMC operation were explained as well. A hardware system was built in the laboratory and several experiments were carried out to verify the operational feasibility of the system. The developed system can be utilized to analyze various mechanical and electrical characteristics of an RMC for a PMSM drive system and verify optimal control schemes in future research.

\section{Acknowledgements}

This work was supported by the Basic Science Research Program through the National Research Foundation of Korea (NRF) funded by the Ministry of Education (No. 2013R1A1A2A10006090).

\section{References}

[1] T. Friedli, J. W. Kolar, J. Rodriguez, and P. W. Wheeler, "Comparative evaluation of three-phase acac matrix converter and voltage dc-link back to-back converter systems," IEEE Trans. Ind. Electron., vol. 
59, no. 12, pp. 4487-4510, Dec. 2012.

[2] J. W. Kolar, T. Friedli, J. Rodriguez, and P. W. Wheeler, "Review of three-phase PWM ac-ac converter topologies," IEEE Trans. Ind. Electron. Special Section Matrix Converters, vol. 58, no. 11, pp. 4988-5006, Nov. 2011.

[3] P. Szcześniak, "Three-phase AC-AC power converters based on matrix converter topology," Springer, 2013.

[4] P. Nielsen, "The matrix converter for an induction motor drive," Ph.D. Thesis, Aalborg University, Denmark, 1996.

[5] K. Iimori, K. Shinohara, O. Tarumi, Z. Fu, and M. Muroya, "New current-controlled PWM rectifiervoltage source inverter without DC link components," in Proc. PCC, pp. 783-786, 1997.

[6] J.W. Kolar, F. Schafmeister, S. D. Round, and H. Ertl, "Novel three-phase ac-ac sparse matrix converters," IEEE Trans. Power Electron., vol. 22, no. 5, pp. 1649-1661, Sep. 2007.

[7] L.Wei, T. A. Lipo, and H.Chan, "Matrix converter topologies with reduced number of switches," in Proc. PESC., vol. 1, pp. 57-63, 2002.

[8] Y. Bak, E. Lee, and K. B. Lee, "An indirect matrix converter for dual output AC drive system with reduced number of power transistors," in Proc. CENCON, pp. 360-364, 2014.

[9] X. Liu, P. Wang, P. C. Loh, and F. Blaabjerg, "A compact three-phase single-input/dual-output matrix converter," IEEE Trans. Ind. Electron., vol. 59, no. 1, pp. 6-16, Jan. 2012.

[10] T. Wijekoon, C. Klumpner, P. Zanchetta, and P. W. Wheeler, "Implementation of a hybrid AC-AC direct power converter with unity voltage transfer," IEEE Trans. Power Electron., vol. 23, no. 4, pp. 1918-1926, Jul. 2008.

[11] K. Park, K. B. Lee, and F. Blaabjerg, "Improving output performance of a Z-source sparse matrix converter under unbalanced input-voltage conditions," IEEE Trans. Power Electron., vol. 27, no. 4, pp. 2043-2054, Apr. 2012.

[12] B. Ge, Q. Lei, W. Qian, and F. Z. Peng, "A family of Z-source matrix converters," IEEE Trans. Ind. Electron., vol. 59, no. 1, pp. 35-46, Jan. 2012.

[13] X. Liu, P. C. Loh, P. Wang, F. Blaabjerg, Y. Tang, and E. A. Al-Ammar, "Distributed generation using indirect matrix converter in reverse power mode," IEEE Trans. Power Electron., vol. 28, no. 3, pp. 1072-1082, Mar. 2013.

[14] X. Liu, P. Wang, P. C. Loh, and F. Blaabjerg, "Distributed generation interface using indirect matrix converter in boost mode with controllable grid side reactive power," in Proc. IPEC, pp. 59-64, 2012.

[15] Z. Fedyczak, G. Tadra, and M. Klytta, "Implementation of the current source matrix converter with space vector modulation," in Proc. EPE/PEMC, pp. T2-97-T2-102, 2010.
[16] K. Park and K. -B. Lee, "Hardware Simulator Development for a 3-Parallel Grid-connected PMSG Wind Power System," J. of Power Electron., vol. 10, no. 5, pp. 555-562, Sept. 2010.

[17] A.K. Sahoo, K. Basu, N. Mohan, "Systematic Input Filter Design of Matrix Converter by Analytical Estimation of RMS Current Ripple," IEEE Trans. Industrial Electronics, vol. 62, no. 1, pp. 132-143, 2015.

[18] C. Klumpner "An indirect matrix converter with a cost effective protection and control", in Proc. EPE, pp.1-11 2005.

[19] M. Aner, N. Benaifa, E. Nowicki, "A PMSM drive design with inverter-stage soft switching hysteresis current control and space vector modulation for twolevel operation of a very sparse matrix converter," In Proc. EPEC, pp. 22-23, 2009.

[20] T. D. Nguyen and H.-H. Lee, "Dual three-phase indirect matrix converter with carrier-based PWM method," IEEE Trans. Power Electron., vol. 29, no. 2, pp. 569-581, Feb. 2014.

[21] A. M. Hava, R. J. Kerkman, and T. A. Lipo, "Carrierbased PWM-VSI overmodulation strategies: Analysis, comparison and design," IEEE Trans. Power Electron., vol. 13, no. 4, pp. 674-689, Jul. 1998.

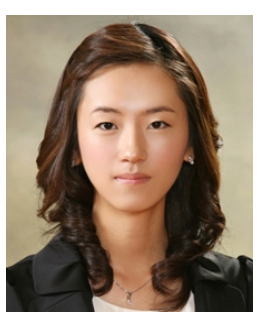

Eunsil Lee She received B.S and M.S degree in electrical and computer engineering from Ajou University, Korea, in 2010 and 2012, respectively, and the $\mathrm{Ph} . \mathrm{D}$ degree in electrical and computer engineering from Ajou University, Korea, in 2015 .

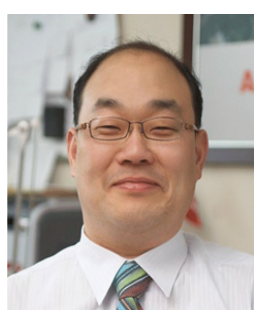

Kyo-Beum Lee He received B.S and M.S degree in electrical and electronic engineering from Ajou University, Korea, in 1997 and 1999, respectively, and the Ph.D degree in electrical engineering from Korea University, Korea, in 2003. From 2003 to 2006, he was with the Institute of Energy Technology, Aalborg University, Denmark. From 2006 to 2007, he was with the division of electronics and information engineering, Chonbuk national university Korea. In 2007, he joined the school of electrical and computer engineering, Ajou university, His research interests include electric machine drives, renewable power generations, and electric vehicle applications. 